Article

\title{
Flipped Classroom: Active Methodology for Sustainable Learning in Higher Education during Social Distancing Due to COVID-19
}

\author{
Joshua Collado-Valero ${ }^{1}$, Gemma Rodríguez-Infante ${ }^{1}$, Marta Romero-González ${ }^{2}$, Sara Gamboa-Ternero ${ }^{2}$, \\ Ignasi Navarro-Soria ${ }^{3}$ (D) and Rocío Lavigne-Cerván ${ }^{1, *(D)}$
}

1 Department of Developmental and Educational Psychology, University of Malaga, 29071 Malaga, Spain; joshuaeducacion@gmail.com (J.C.-V.); gri@uma.es (G.R.-I.)

2 Neuropsipe, Child and Adolescent Neuroscience Center, 29010 Malaga, Spain; martarogo@gmail.com (M.R.-G.); sgamboaternero@gmail.com (S.G.-T.)

3 Department of Developmental and Educational Psychology, University of Alicante, 03690 Alicante, Spain; ignasi.navarro@ua.es

* Correspondence: rlc@uma.es

check for

updates

Citation: Collado-Valero, J.;

Rodríguez-Infante, G.;

Romero-González, M.;

Gamboa-Ternero, S.; Navarro-Soria, I.;

Lavigne-Cerván, R. Flipped

Classroom: Active Methodology for

Sustainable Learning in Higher

Education during Social Distancing

Due to COVID-19. Sustainability 2021,

13, 5336. https://doi.org/10.3390/

su13105336

Academic Editors: José

Antonio Marín-Marín,

Santiago Alonso-García and

Fernando José Sadio Ramos

Received: 28 March 2021

Accepted: 8 May 2021

Published: 11 May 2021

Publisher's Note: MDPI stays neutral with regard to jurisdictional claims in published maps and institutional affiliations.

Copyright: (C) 2021 by the authors. Licensee MDPI, Basel, Switzerland. This article is an open access article distributed under the terms and conditions of the Creative Commons Attribution (CC BY) license (https:// creativecommons.org/licenses/by/ $4.0 /)$.
Abstract: Methodological guidelines for virtual teaching during the lockdown, tailored to Flipped Classroom, are suggested by the Spanish University Education System. This educational methodology is recommended as an effective method for distance learning due to COVID-19 by several articles, studies, research, universities and institutions in different countries around the world. However, what is the impact of these extreme circumstances on the implementation of Flipped Classroom in Higher Education? The study design is a descriptive and correlational research that compares the frequency of the implementation of Flipped Classroom before and during social distancing. This information is provided by the participants, university professors from the Faculty of Education Sciences of the University of Malaga, through an ad hoc questionnaire. The results reveal a significant increase in the frequency of Flipped Classroom sessions $(z=-4.80 ; p<.001)$ during the lockdown. The data also show a significant increase in the quantity and variety of didactic resources $(t=-2.390$; $p=0.021)$, mainly those related to Flipped Classroom, with video $(z=-2.860, p=0.004)$ and audio $(z=-2.049, p=0.040)$ files. University professors consider virtual teaching during the lockdown an opportunity for Flipped Classroom and digital skills that could improve the quality of university educational methodology.

Keywords: flipped classroom; active methodology; quality education; higher education; university professors; distance learning; social distancing; COVID-19

\section{Introduction}

On 13 January 2020, the first case of COVID-19 was diagnosed outside China [1]. Weeks later, on 31 January 2020, the first case of COVID-19 was diagnosed in Spain [2]. On 27 February 2020, the University of Malaga sends a communication related to the new coronavirus species and, on 9 March 2020, it reports the first case [3]. Meanwhile, the disease continues to expand, spreading to more than 200 countries and increasing to more than 10,000,000 infected [2], causing the closure of universities in more than 180 territories and affecting millions of students worldwide [4]. Face-to-face teaching is no longer a possible alternative and distance learning becomes the only option. On 12 March 2020, the provisional suspension of face-to-face teaching is announced [3], however, university students will not return to their educational centres until the end of the academic year. On 14 March 2020 [5], the state of alarm is declared, starting the lockdown. Since then, the new variant of coronavirus has not stopped reproducing.

Consequently, in the Spanish University Education System, on 11 April 2020 [3], the University of Malaga, the Andalusian Single District and the Spanish Network of 
University Quality Agencies publish methodological guidelines, at provincial, regional and national level, for university education during social distancing. These texts state the need to adapt the educational methodologies of face-to-face teaching to distance learning and authorize university departments to make the necessary modifications to the teaching guides. For this reason, the state of alarm has been an important challenge for university professors, imposing the deconstruction and reconstruction of educational methodology; however, because not all educational methodologies are proportionally adapted to distance learning, whether traditional or alternative, not all university professors have experienced the same difficulties in restructuring the teaching guides.

\subsection{The Traditional Model and Methodological Orientations}

The Traditional Model, the most frequent university educational methodology in the educational system $[6,7]$, presents incompatibility with the methodological guidelines for university education during social distancing due to the way it comprises theoretical teaching, practical activity and educational evaluation.

Firstly, theoretical teaching plays a major role in traditional educational methodology. This is based on the transmission of knowledge through an Expositive Approach $[8,9]$ within the established teaching schedule; what is commonly known as master classes [10-12]. A practical alternative for adapting the theoretical teaching of the Traditional Model to distance learning is the delivery of master classes through synchronous communication tools, live broadcasted image and sound through virtual platforms such as Big Blue Button, Google Meet, Microsoft Teams, Skype or Zoom. However, the methodological guidelines proposed by the University of Malaga recommended avoiding master classes [3] through synchronous communication tools, due to the functional complexity and technical problems in some virtual platforms [13]. Secondly, practical activity, as opposed to theoretical teaching, plays a minor role in traditional educational methodology. Characterized by repetition, internalization and automation activities outside the established teaching schedule, it is commonly known as homework [10-12]. Nevertheless, the distance learning guide recommend some activities of "special relevance" reasonably different from the characteristic homework of the Traditional Model [3]. Thirdly, traditional educational evaluation is based on the final summative assessment [14-16], the evaluation of the academic result through quantitative procedures. The assessment instrument par excellence of this educational methodology is the exam $[17,18]$. However, distance learning guide recommend not making excessive use of the exam [13] due to obvious drawbacks, such as guaranteeing the authorship of university students.

Thus, without assessing the effectiveness of the Traditional Model, as far as virtual teaching is concerned, it is stated that the methodological guidelines proposed by education professionals disqualify the traditional educational methodology as an effective method for distance learning during the lockdown.

\subsection{Flipped Classroom and Methodological Orientations}

Blended Learning is an educational methodology that combines face-to-face teaching with distance learning [19,20]. Flipped Classroom, a form of Blended Learning [21], is an educational methodology that exchanges the timing and location of theoretical teaching and practical activity of the traditional educational model [22-24]. Theoretical teaching takes place outside the established teaching schedule and outside the educational centre, through distance learning; while practical activity is included within the established teaching schedule and inside the educational centre, through face-to-face teaching. At first glance, Flipped Classroom may seem to be an educational methodology that is incompatible with virtual teaching during social distancing as, at the very least, it requires semi-presential learning; however, if one considers the possibility of face-to-face teaching through synchronous communication tools that allow immediate communication between university professors and students, this educational methodology is an effective alternative to distance learning [25]. 
On the one hand, there is a wide variety of teaching resources, both audio-visual and non-audio-visual, to move the theoretical activity outside the established teaching schedule. Audio-visual resources are presented as the most effective [26-28]. The most characteristic audio-visual resource is video [29], especially, developed ad hoc [30]. This educational practice coincides with the methodological guidelines proposed by the University of Malaga, the Andalusian Single District and the Spanish Network of University Quality Agencies, which recommend "recording the sessions" of theoretical teaching [3]. To this end, the University of Malaga proposes guidelines for the training of university professors in the production of videos, through computer applications such as QuickTime, and the publication of videos, through virtual platforms such as YouTube or cloud storage such as Google Drive or One Drive [13]. Slides presentations composed of image, sound and text, often developed $A d \mathrm{Hoc}$, are interesting. The distance learning guide incorporates the necessary guidelines for inserting video or audio files into slide presentations such as PowerPoint [13]. Nonaudio-visual resources, such as slide presentations without images and sound or text, are presented as the least effective tool [26-28]; moreover, they are less typical of Flipped Classroom and more characteristic of precursor educational methodologies such as Peer Instruction [31] or Just in Time Teaching [32].

On the other hand, the practical activity of this educational methodology coincides with the recommendations made by educational professionals to promote "alternative methodologies" [3]. Flipped Classroom, as an active educational methodology [33,34] is based on constructivist educational methodologies [21]. In relation to cognitive constructivism [35], Flipped Classroom is linked to Project-Based [36], Problem-Based Learning [37] or Thinking-Based Learning [38]. These educational practices coincide with the methodological guidelines proposed by the University of Malaga, which encourage research through projects, problem solving through cases or reflection through portfolios, reports or diaries [3]. To this end, the distance learning guide describes all these teaching activities [13]. In relation to social constructivism [39], Flipped Classroom is linked to Cooperative Learning and Collaborative Learning [40,41]. These educational practices also coincide with the methodological guidelines proposed by the University of Malaga which suggest limiting synchronous communication tools to "collaborative activities" within the established teaching schedule [3]. To this end, the distance learning guide indicates how to develop these practical teaching sessions through virtual platforms such as Big Blue Button, Google Meet or Microsoft Teams [13]. Other activities characteristic of this educational methodology, such as conversations and debates, also reflected in the distance learning guide, are promoted through chats and forums [3]. Finally, the extensive variety of didactic activities encourages continuous formative evaluation [14-16], academic process assessment, recommended by the University of Malaga, the Andalusian Single District and the Spanish Network of University Quality Agencies [3].

In short, education professionals demand that face-to-face virtual meetings, between students and teaching professionals, take place during the established teaching schedule. However, they recommend that these should not be master classes nor theoretical teaching, but rather didactic activities with practical teaching. This suggests the transfer of theoretical teaching outside the established teaching schedule, through audio-visual resources, and the inclusion of practical teaching within the established teaching schedule, through synchronous communication tools. Undoubtedly, Flipped Classroom is especially adapted to the recommendations made by the University of Malaga, the Andalusian Single District and the Spanish Network of University Quality Agencies [3]. For this reason, without assessing the effectiveness of Flipped Classroom, which has been defended by numerous studies, as far as virtual teaching is concerned, it is stated that the methodological guidelines proposed by education professionals qualify this alternative educational methodology as effective for distance learning during the lockdown. 


\subsection{Flipped Classroom in COVID-19 Pandemic}

Although the University of Málaga, the Andalusian Single District and the Spanish Network of University Quality Agencies do not make specific reference to Flipped Classroom in their virtual teaching guide [3], they do indirectly recommend this educational methodology for distance learning during the lockdown. In any case, the methodological guidelines, suggested at the provincial, regional and national levels by the Spanish University Education System, are not the only evidence of a possible connection between Flipped Classroom and these extreme circumstances.

In the educational field, at an international level, there is a direct link between this educational methodology and COVID-19 pandemic. In the last decade, between 1 January 2011 and 1 January 2021, the term Flipped Classroom reached its highest popularity during the lockdown, increasing its search frequency in Google Trends by up to 200\% compared to the previous months [42]. This tendency coincides with an increase in scientific publications linking the two topics. Several teaching professionals begin to disseminate their different experiences of methodological adaptation, associated with Flipped Classroom and COVID19 pandemic, in university degrees such as Computer Science [43], Chemistry [44] or Medicine [45]. Several authors come to the same conclusions and argue that this educational methodology can solve the difficulties of virtual teaching due to social distancing [46,47], and some even claim that the health crisis is a special opportunity for the progress of education $[48,49]$.

The methodological guidelines for virtual teaching during social distancing tailored to Flipped Classroom, the increase in internet searches and scientific articles on this educational methodology during the lockdown, as well as the various statements of the educational experts, induce to deduce an increase of Flipped Classroom implementation related to COVID-19 pandemic. These speculations open a gap that needs to be filled with solid data obtained through statistical analysis and research method. All this information inspires the following research question: What is really the impact of COVID-19, the state of alarm and social distancing on the implementation of the university educational methodology known as Flipped Classroom? Similarly, there are derivative questions: Has the frequency of Flipped Classroom sessions increased during the lockdown? Consequently, has the presence of didactic resources typical of this educational methodology increased during the lockdown? In this case, what would be the origin of these methodological modifications? Why would teaching professionals have increased the frequency of Flipped Classroom sessions? Would teaching professionals consider Flipped Classroom to be an effective methodology for distance learning during lockdown? How will these extreme circumstances affect university education?

To date, little research has assessed the impact that virtual teaching due to social distancing has had on university methodology, and the increase or decrease of its models, approaches, methods and resources; let alone in specific relation to alternative methodologies such as Flipped Classroom. Although several articles speculate the increase of the implementation of Flipped Classroom during the lockdown [50,51], and a few others begin to evaluate its positive impact $[52,53]$, it is necessary to empirically demonstrate the connection between the two variables. For this reason, the primary objective of the study is to analyse the impact of COVID-19, the state of alarm and social distancing on the implementation of the university educational methodology known as Flipped Classroom. To this end, three specific objectives have been determined: $\left(\mathrm{O}_{1}\right)$ to compare the frequency of Flipped Classroom sessions before and during the lockdown; $\left(\mathrm{O}_{2}\right)$ to compare the presence of didactic resources specific to this educational methodology before and during the lockdown; $\left(\mathrm{O}_{3}\right)$ to find out the teaching professionals personal considerations on the repercussion of virtual teaching during social distancing on the quality of university educational methodology. The commitment of university professors to the recommendations made would imply a series of hypotheses: $\left(\mathrm{H}_{1}\right)$ the statistically significant increase of Flipped Classroom sessions during the lockdown; $\left(\mathrm{H}_{2}\right)$ the statistically significant increase in the presence of didactic resources typical to this educational methodology during the 
lockdown, particularly ad hoc video, non-ad hoc video and slide presentations with audio; as well as $\left(\mathrm{H}_{3}\right)$ the positive considerations of Flipped Classroom by educational experts.

\section{Materials and Methods}

\subsection{Design}

The study design is a descriptive and correlational research developed through quantitative analysis. This method allowed data to be collected at two different time intervals, results to be compared and correlations to be analysed. Its structure was intended to simulate a quasi-experimental research with a pre-test-intervention-post-test design. The pre-test and post-test phases would involve calculating the dependent variable: the frequency of implementation of Flipped Classroom, both before and during the intervention, or in this case, the exposure to the independent variable: the lockdown. Consequently, by estimating the frequency of implementation of the Flipped Classroom before the lockdown (Pre) and during the lockdown (Post) and comparing the results (Pre-Post), the positive, negative or null correlation between COVID-19, the state of alarm and social distancing and the implementation of the university educational methodology known as Flipped Classroom was established.

\subsection{Participants}

The study population, consisting of between 200 and 250 individuals, was the total number of university professors of the Faculty of Education Sciences of the University of Malaga. More than a quarter of the educational experts from this specific centre and this particular university, approximately 70 subjects, were contacted and invited to participate in the research. Finally, the study sample consisted of $18.8 \%(n=45)$ of the total of university professors from the Faculty of Educational Sciences of the University of Malaga, from its five different departments: Didactics and School Organization $(n=12)$, Didactics of Languages, Arts and Sport $(n=11)$, Theory and History of Education and Methods of Research and Diagnosis in Education $(n=8)$, Didactics of Mathematics, Social Sciences and Experimental Sciences $(n=7)$ and Developmental and Educational Psychology $(n=7)$. As an inclusion criterion, the participation of university professors who had given face-to-face teaching before social distancing and virtual teaching during social distancing was established. The non-participation of university professors whose teaching sessions during social distancing consisted exclusively of tutoring Practicum, Final Degree Project or Final Master Project was set as an exclusion criterion, due to the fact that this type of activity is not compatible with Flipped Classroom. Regarding sex and age, the study sample was made up of $35.6 \%$ $(n=16)$ men and $64.4 \%(n=29)$ women aged between 27 and $65(\mathrm{M}=47.44 ; \mathrm{SD}=9.48)$.

\subsection{Instrument}

The data collection instrument (Appendix A) consisted of an online questionnaire developed ad hoc through the virtual platform Google Form, following the recommendations of educational research professionals [54]. The questionnaire consisted of 6 blocks and 20 items. Block 0 contains 2 items referring to exploratory information: sex and age. Block 1 contained a single dichotomous response item that collect information on how much of the sample knows about Flipped Classroom. Block 2 did not contain any items; however, it presented the definition of Flipped Classroom accompanied by audio-visual resources with additional information for professors who are unfamiliar with this educational methodology. The main blocks of the online questionnaire were Block 3 and Block 4, as they allowed the collection of data related to the first specific objectives. $\left(\mathrm{O}_{1}\right)$ To compare the frequency of Flipped Classroom sessions before and during social distancing, 2 items with a five-point Likert Scale were used: (1) never: no or almost no sessions, (2) low frequently: less than half of the sessions, (3) medium frequency: half of the sessions, (4) high frequency: more than half of the sessions, and (5) always: all or almost all sessions. $\left(\mathrm{O}_{2}\right)$ To compare the frequency of didactic resources of this educational methodology before and during social distancing, 10 items with a five-point Likert Scale were used: (1) never: no or almost no 
sessions, (2) low frequently: less than half of the sessions, (3) medium frequency: half of the sessions, (4) high frequency: more than half of the sessions, and (5) always: all or almost all sessions; 2 items for each type of resource:

- Ad hoc video: video made personally by the university professor and specifically for the teaching session.

- Non-Ad hoc video: video not made personally by the university professor neither specifically for the teaching session.

- $\quad$ Slide presentations with audio: slide presentation, such as PowerPoint or Google Slides, with audio files of the university professor own voice explaining or complementing the written text.

- $\quad$ Slide presentations without audio: slide presentation, such as PowerPoint or Google Slides, without audio files of the university professor own voice explaining or complementing the written text.

- $\quad$ Text: Book chapters, articles, news, etc.

Other items in Block 3 and Block 4, together with the only item in Block 5, which present a multi-answer format with between three and four responses alternatives, were related to the last specific objective, $\left(\mathrm{O}_{3}\right)$ to find out the teaching professionals personal considerations on the repercussion of distance teaching during social distancing on the quality of university educational methodology.

\subsection{Procedure}

On 12 March 2020, after the provisional suspension of face-to-face teaching [3], the analysis of the methodological guidelines for virtual teaching for social distancing began, at a provincial, regional and national level. The extensive review of the different documents, the methodological guidelines for virtual teaching during social distancing tailored to Flipped Classroom, and other facts such as the increase in internet searches and scientific articles on this educational methodology during the lockdown, as well as the various statements of the educational experts, oriented the general and specific objectives of the research towards Flipped Classroom. After the definitive suspension of face-to-face teaching on 1 April 2020 [3], the development of an online questionnaire started, with the primary objective of analysing the implementation of this educational methodology before and during the lockdown. After the end of the academic year, on 1 July 2020, the individual sending of the online questionnaire via email began. The online questionnaire remained open for completion for a full month. Finally, the Statistical Package for the Social Sciences (v.25.0) allowed the statistical analysis of the data collected through Student's t-test and the Wilcoxon rank test.

\subsection{Research Ethics}

This study was carried out in accordance with the ethical principles of the Declaration of Helsinki and the Ethics Committee and Vice-Rectorate for Research and Knowledge Transfer of the University of Alicante (UA-2020-05-12).

\section{Results}

With the specific objective of $\left(\mathrm{O}_{1}\right)$ comparing the frequency of Flipped Classroom sessions before and during the lockdown, a statistical analysis was performed. Firstly, the Kolmogorov-Smirnov test did not verify the normality for the distribution of the frequency of Flipped Classroom sessions. For this reason, the Wilcoxon rank test for paired samples was applied (Table 1). 
Table 1. Wilcoxon signed-rank test for Flipped Classroom sessions.

\begin{tabular}{cccc}
\hline & & \multicolumn{2}{c}{ Flipped Classroom Sessions } \\
\cline { 3 - 4 } & & $\boldsymbol{n}$ & $\%$ \\
\hline \multirow{3}{*}{ Post-Pre } & Positive ranges (Post > Pre) & 30 & 66,7 \\
& Negative ranges (Post < Pre) & 1 & 2,2 \\
& Ties (Post = Pre) & 14 & 31,1 \\
\hline
\end{tabular}

The Wilcoxon rank test showed a statistically significant increase in the frequency of Flipped Classroom sessions $(z=-4.80 ; p<0.001)$ during social distancing. Secondly, the frequency table was observed to analyse its distribution (Table 2). The difference in frequencies between before and during the lockdown was also calculated (Table 2). The results were presented in a graph, in particular a bar chart, to facilitate comparison of the data before (Figure 1) and during lockdown (Figure 2).

Table 2. Distribution of the frequency of Flipped Classroom sessions.

\begin{tabular}{ccccccc}
\hline Flipped Classroom & \multicolumn{2}{c}{ Pre } & \multicolumn{3}{c}{ Post } & \multicolumn{2}{c}{ Post-Pre } \\
\cline { 2 - 7 } Session Frequency & $\boldsymbol{n}$ & $\%$ & $\boldsymbol{n}$ & $\%$ & $\boldsymbol{n}$ & $\%$ \\
\hline Never $^{1}$ & 17 & 37.8 & 6 & 13.3 & -11 & -24.5 \\
Low frequency $^{2}$ & 13 & 28.9 & 9 & 20.0 & -4 & -8.9 \\
Medium frequency $^{3}$ & 10 & 22.2 & 9 & 20.0 & -1 & -2.2 \\
High frequency $^{4}$ & 4 & 8.9 & 15 & 33.3 & 11 & 24.4 \\
Always $^{5}$ & 1 & 2.2 & 6 & 13.3 & 5 & 11.1 \\
\hline
\end{tabular}

${ }^{1}$ No or almost no sessions; ${ }^{2}$ Less than half of the sessions; ${ }^{3}$ Half of the sessions; ${ }^{4}$ More than half of the sessions ${ }^{5}$ All or almost all sessions.

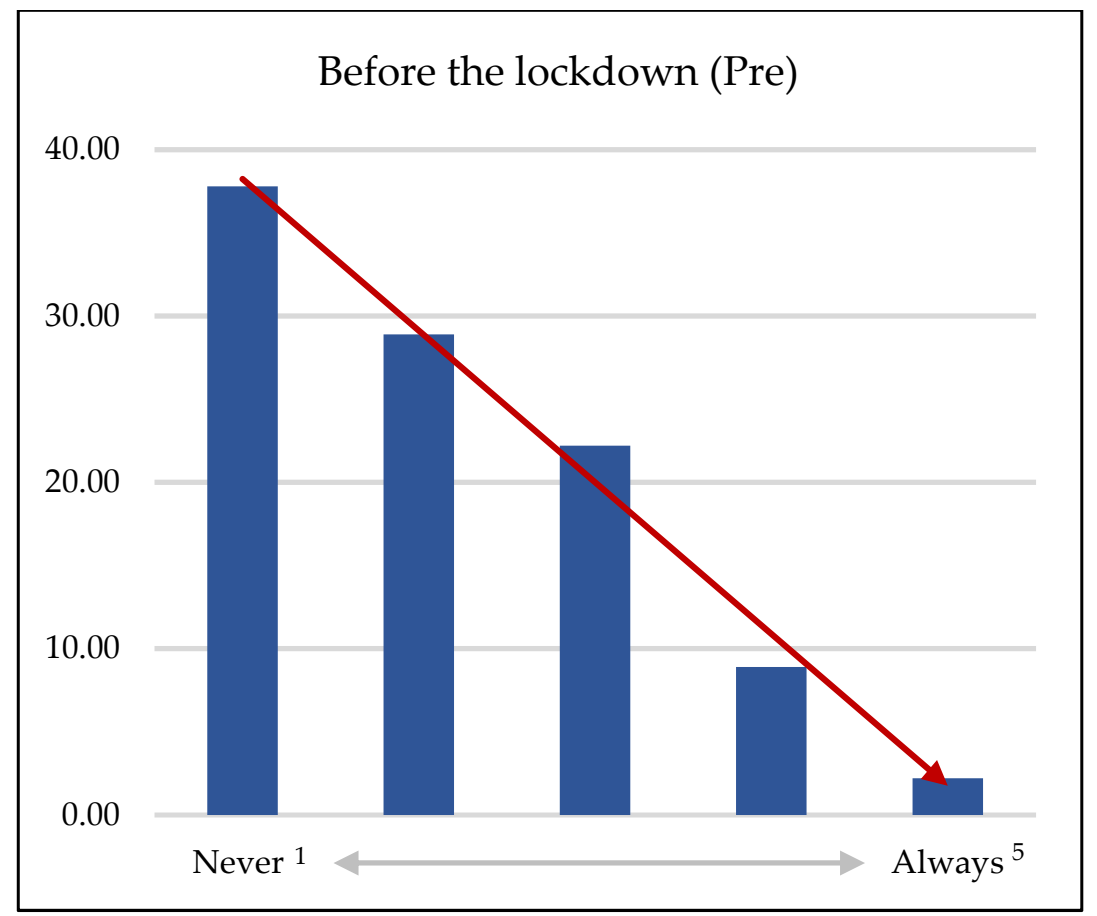

Figure 1. Flipped Classroom frequency before the lockdown. ${ }^{1}$ No or almost no sessions; ${ }^{5}$ All or almost all sessions. 


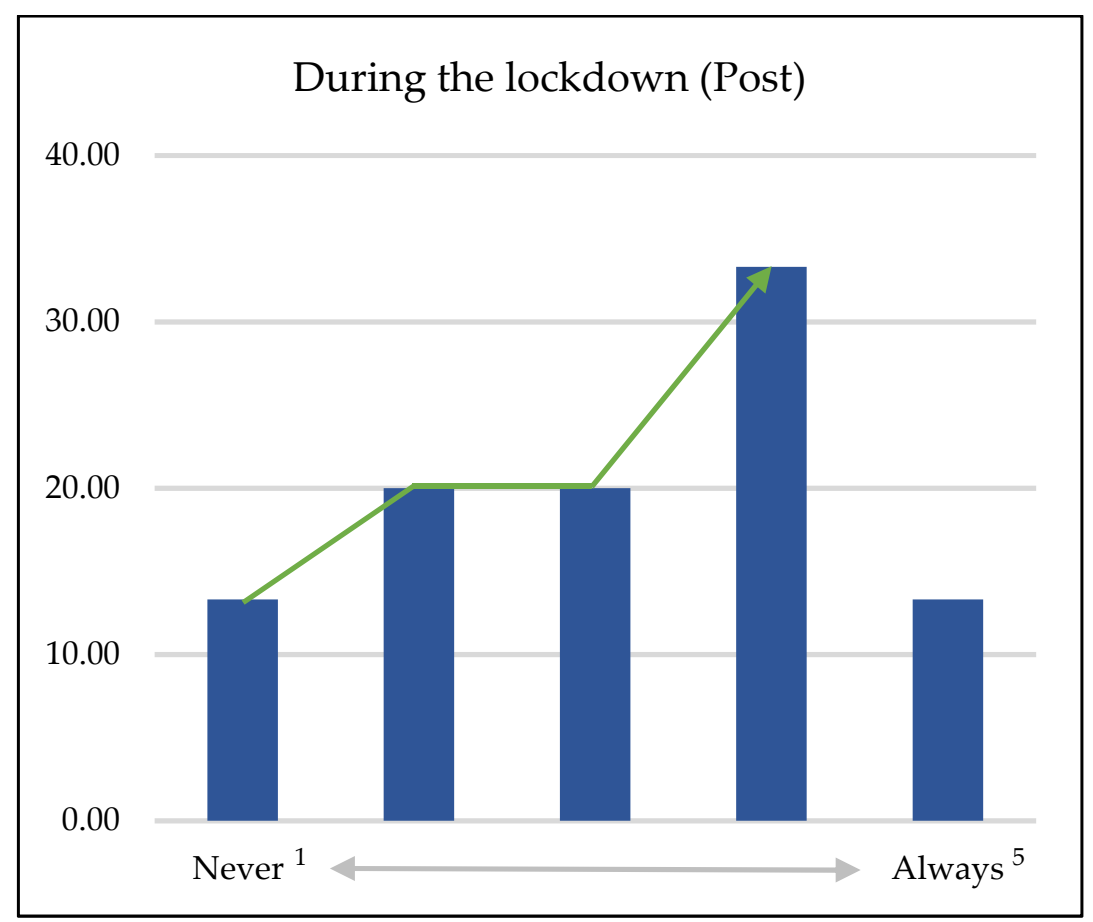

Figure 2. Flipped Classroom frequency during the lockdown. ${ }^{1}$ No or almost no sessions; ${ }^{5}$ All or almost all sessions.

The analysis of central tendency, median (Md) and mode (Mo), coincides with the previous results, revealing differences between the frequency of Flipped Classroom sessions before social distancing $(\mathrm{Md}=2.0 ; \mathrm{Mo}=1.0)$ and during social distancing $(\mathrm{Md}=3.0$; Mo $=4.0$ ).

With the specific objective of $\left(\mathrm{O}_{2}\right)$ comparing the frequency of didactic resources specific to this educational methodology before and during the lockdown, firstly, a general analysis of all the didactic resources, not categorized by type, was carried out. The Kolmogorov-Smirnov test verified the normality for the distribution of the frequency of all didactic resources before social distancing $(k s=0.121 ; p=0.096)$ and during social distancing $(k s=0.118 ; p=0.128)$. For this reason, Student's $t$-test for related groups was applied. The results indicated the statistically significant increase in the frequency of Flipped Classroom teaching resources $(t=-2.390 ; p=0.021)$ during social distancing, and differences in central tendency, mean $(\mathrm{M})$, and dispersion measures, standard deviation $(\mathrm{SD})$, between before social distancing $(\mathrm{M}=12.87 ; \mathrm{SD}=4.708)$ and during social distancing $(\mathrm{M}=14.07 ; \mathrm{SD}=4.356)$.

Secondly, a specific analysis of each didactic resource, now categorized by type, was carried out. The Kolmogorov-Smirnov test did not verify the normality for the frequency distribution of each resource. For this reason, the Wilcoxon rank test for paired samples was applied (Table 3). 
Table 3. Wilcoxon rank test for Flipped Classroom teaching resources.

\begin{tabular}{|c|c|c|c|c|c|c|c|}
\hline \multirow{3}{*}{\multicolumn{2}{|c|}{ Type of Resource }} & \multicolumn{6}{|c|}{ Pre-Post } \\
\hline & & \multicolumn{2}{|c|}{$\begin{array}{l}\text { Positive Ranges } \\
\text { (Post > Pre) }\end{array}$} & \multicolumn{2}{|c|}{$\begin{array}{l}\text { Negative Ranges } \\
\text { (Post < Pre) }\end{array}$} & \multicolumn{2}{|c|}{$\begin{array}{c}\text { Ties } \\
\text { (Post = Pre) }\end{array}$} \\
\hline & & $n$ & $\%$ & $n$ & $\%$ & $n$ & $\%$ \\
\hline \multirow{2}{*}{ Video } & Ad Hoc & 12 & 26.7 & 6 & 13.3 & 27 & 60 \\
\hline & No Ad Hoc & 17 & 37.8 & 5 & 11.1 & 23 & 51.1 \\
\hline \multirow{2}{*}{ Slides } & Audio & 17 & 37.8 & 8 & 17.8 & 20 & 44.4 \\
\hline & No audio & 9 & 20 & 15 & 33.3 & 21 & 46.7 \\
\hline Text & & 8 & 17.8 & 9 & 20 & 28 & 62.2 \\
\hline
\end{tabular}

The Wilcoxon rank test showed the statistically significant increase in the frequency of non-ad hoc video $(z=-2.860, p=0.004)$ and slide presentations with audio $(z=-2.049$, $p=0.040)$ during social distancing. However, the results indicated the absence of statistically significant differences for ad hoc video $(z=-1.402 ; p=0.161)$, slide presentations without audio $(z=-0.745 ; p=0.456)$ and text $(z=-0.300 ; p=0.764)$. The frequency table before social distancing (Table A1) and during social distancing (Table A2) were also observed (Appendix B) to analyse the frequency distribution. The difference in frequencies between before and during the lockdown (Table A3) was also calculated (Appendix B). The results were presented in a graph, in particular a bar chart, to facilitate comparison of the data before and during lockdown (Figure 3).

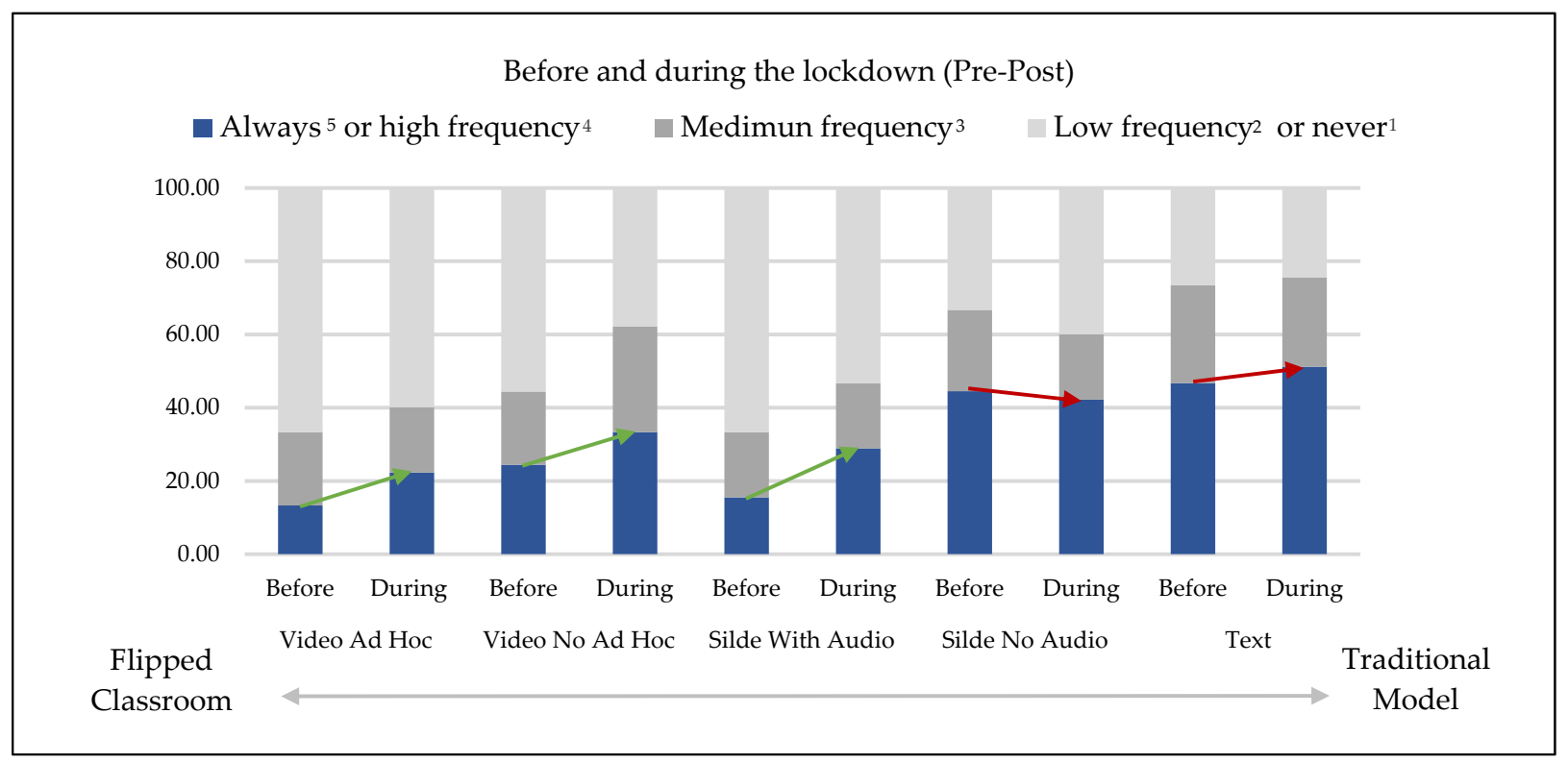

Figure 3. Comparison of teaching resources before and during the lockdown. ${ }^{1}$ No or almost no sessions; ${ }^{2}$ Less than half of the sessions; ${ }^{3}$ Half of the sessions; ${ }^{4}$ More than half of the sessions; ${ }^{5}$ All or almost all sessions.

The central tendency analysis of the didactic resources coincides with the previous results. The increase in the frequency of the non-ad hoc video from before social distancing $(\mathrm{Md}=2)$ to during social distancing $(\mathrm{Md}=3)$ and the increase in the frequency of slide presentations with audio from before social distancing $(\mathrm{Md}=1)$ to during social distancing $(\mathrm{Md}=2)$ stand out above the rest of the teaching resources.

Finally, with the specific objective of $\left(\mathrm{O}_{3}\right)$ finding out the teaching professionals personal considerations on the repercussion of virtual teaching during the lockdown on the quality of university educational methodology, the frequency table (Table A4) was observed (Appendix B). In total, 86.7\% of university professors consider that COVID-19, the state of alarm and social distancing have favoured the implementation of alternative 
educational methodologies. Of these, $79.5 \%$ stated that distance learning has promoted Flipped Classroom as well as other educational methodologies, while $20.5 \%$ stated that virtual teaching has promoted Flipped Classroom over other educational methodologies. Additionally, 88.9\% of university professors consider that COVID-19, the state of alarm and social distancing have favoured the development of teaching skills, such as those related to the didactic resources inherent to this educational methodology, especially audio-visual resources. Among these, 75\% state that the teaching skills developed have enabled university professors to implement both Flipped Classroom and other educational methodologies, while $25 \%$ state that the teaching skills developed have qualified university professors to implement Flipped Classroom over other educational methodologies. For these two reasons, among the $88.9 \%$ of the participants who consider virtual teaching during social distancing an opportunity for Flipped Classroom, $67.5 \%$ of the teaching professionals value the possibility of improving the quality of the university educational methodology.

\section{Discussion and Conclusions}

The declared state of alarm and mobility restrictions make face-to-face teaching an impracticable alternative; instead, virtual learning becomes the only viable option. For this reason, at a provincial, regional and national level, important changes are being demanded in university educational methodology. On the one hand, Blended Learning is no longer one of the best options but one of the few alternatives. Flipped Classroom is boosted by the circumstances. In the Faculty of Educational Sciences of the University of Málaga, the correlation between this educational methodology and COVID-19 pandemic is studied.

\subsection{Frequency of Implementation of Flipped Classroom before and during the Lockdown}

The results reveal an increase in the implementation of Flipped Classroom during the lockdown. In total, $66.7 \%$ of the university professors increase the number of Flipped Classroom sessions; for this reason, the implementation of this educational methodology in more than half of the teaching sessions increases by more than $300 \%$ during social distancing. On the other hand, the didactic resources of this educational methodology cease to be complementary and become essential. Consequently, the null hypothesis is rejected and $\left(\mathrm{H}_{1}\right)$ the statistically significant increase of Flipped Classroom sessions during the lockdown is confirmed. The data show that the frequency of didactic resources also increases significantly. A total of $55.6 \%$ of university professors increase the frequency of all teaching resources. The increase in the measures of centralization and the decrease in the measures of dispersion reveal the increase in both the quantity and variety of teaching resources. The frequency of alternative didactic resources, audio-visual resources such as Non-ad hoc video and slide presentations with audio, increases significantly. The use in more than half of the teaching sessions of Ad Hoc video and slide presentations with audio, most typical Flipped Classroom didactic resources, increases by $36 \%$ and $85 \%$, respectively, during social distancing. Nevertheless, the frequency of traditional non-audiovisual didactic resources, such as slide presentations without audio and text, less typical of Flipped Classroom, remains relatively stable. Consequently, the null hypothesis for $\left(\mathrm{H}_{2}\right)$ the statistically significant increase in the presence of non-ad hoc video and slide presentations with audio is rejected; however, the null hypothesis for $(\mathrm{H} 2)$ the statistically significant increase in the presence of ad hoc video is accepted. In short, the positive correlation between COVID-19, the state of alarm and social distancing and the implementation of the university educational methodology known as Flipped Classroom is declared.

Although the University of Malaga, the Andalusian Single District and the Spanish Network of University Quality Agencies do not make specific reference to Flipped Classroom in their virtual teaching guide [3], this educational methodology is particularly adapted to the recommendations made. The methodological orientations proposed, at provincial level, regional and national level, are in line with the growth of Flipped Classroom. However, correlation does not imply causation. Whereas the results reveal an increase in the implementation of Flipped Classroom related to COVID-19, the state 
of alarm and social distancing and to the methodological guidelines for distance learning during the lockdown; the study design does not allow to state that all these factors caused the growth of this educational methodology.

In any case, to date, no other research has been found that sheds light on the methodological modifications in university education linked to virtual teaching during social distancing, empirically demonstrating the increased of implementation of Flipped Classroom during the lockdown. Although the methodological guidelines for virtual teaching during social distancing tailored to Flipped Classroom, the increase of internet searches and scientific articles on this educational methodology during the lockdown, as well as the different statements of educational experts, induce to deduce an increase of implementation of Flipped Classroom related to COVID-19 pandemic; the results of the study fill a gap open by speculation with solid data obtained through statistical analysis and research methods.

Although few other publications compare the frequency of the implementation of Flipped Classroom before and during the lockdown, other articles, studies, research, universities and institutions in different countries around the world explicitly allude to Flipped Classroom as an effective educational methodology for distance learning during the lockdown, such as the United States [55-58], Canada [59], Spain [60], France [61], United Kingdom [62], Norway [63], Greece [64], Pakistan [65], India [66], China [67], Singapore [68] or New Zealand [69]. Internationally, the United Nations Educational, Scientific and Cultural Organization recommends Flipped Classroom in these circumstances [70]. In addition, Jonathan Bergmann, one of the main representatives of Flipped Classroom, indicates that this educational methodology can solve the difficulties of virtual teaching due to social distancing [71].

\subsection{Teaching Professionals Personal Considerations on Social Distancing}

The results reveal that teaching professionals consider that the circumstances encourage the implementation of Flipped Classroom and favour the development of teaching skills, such as those related to the didactic resources of this educational methodology, especially audio-visual resources. Consequently, the null hypothesis is rejected and $\left(\mathrm{H}_{3}\right)$ the positive considerations about Flipped Classroom by university teachers is confirmed. The data from the study are in line with the results of research carried out by the International Association of Universities. More than 400 universities in over 100 territories affirm that distance learning during the lockdown is "an opportunity" for alternative educational methodologies such as Blended Learning [72]. Undoubtedly, the declaration of the state of alarm and mobility restrictions has had a negative impact at occupational, educational, social and personal levels; however, the methodological orientations proposed by educational professionals seem to be a breath of fresh air for university educational methodology.

Although COVID-19 pandemic raises questions about the future of Higher Education, the teaching professionals value the possibility of improving the quality of the university educational methodology. These extreme circumstances have led to $24.5 \%$ of teachers implementing Flipped Classroom for the first time and $46 \%$ of teachers making Flipped Classroom their main educational methodology. Data from a study conducted by several institutions indicate that $99 \%$ of teachers implementing Flipped Classroom will continue to practice this alternative educational methodology during the next academic year [73]. For this reason, the possibility that the new methodological experiences, originated during the lockdown, are maintained after social distancing is valued, improving the quality of the university educational methodology. In this case, the growth of Flipped Classroom observed during the lockdown would simply be the beginning of an unprecedented increase of Flipped Classroom in university educational methodology.

Ultimately, the research evidences both the increase of implementation of the Flipped Classroom and the positive considerations of teaching professionals; however, the study conclusions go further. This article also provides an example of good practice and teaching strategies for distance learning during the lockdown. The university professors of the Faculty of Educational Sciences of the University of Málaga, educational experts, join 
the global trend of adopting Flipped Classroom as an effective method to overcome the characteristic difficulties of virtual teaching due to social distancing to ensure sustainable education in COVID-19 pandemic.

\section{Study Limitations and Future Research Considerations}

On the one hand, although the sample size is small, it is representative of the study population: the total of university professors of the Faculty of Education Sciences of the University of Malaga. However, the characteristics of the participants do not allow extrapolating the results to other centres and universities, nor generalising the conclusions to a national or international level. On the other hand, to date, no other research has been found that sheds light on the methodological modifications in university education linked to virtual teaching during social distancing. For this reason, discussion with similar studies is practically impossible.

In any case, for future research it would be necessary to increase the sample size as well as to introduce new variables such as the field or branch of knowledge of university professors. It would also be interesting to replicate the study in other universities and countries and compare the results. Additional studies on Flipped Classroom and COVID19 pandemic are encouraged, analysing different variables such as the impact of this educational methodology on learning or the employability of university students.

Author Contributions: J.C.-V., R.L.-C., G.R.-I., M.R.-G., S.G.-T. and I.N.-S. collected and processed the data, performed the analysis, drafted the manuscript, and designed the tables. All authors discussed the results and contributed to the final manuscript. All authors wrote the manuscript with support from J.C.-V. and R.L.-C. J.C.-V. was one of the authors responsible for conceiving the idea of the study. J.C.-V. and R.L.-C. were involved in planning and supervising the study. G.R.-I. and I.N.-S. were responsible for most of the technical aspects of the study and conducted the statistical analyses. All authors have read and agreed to the published version of the manuscript.

Funding: This research received no external funding.

Institutional Review Board Statement: The study was conducted according to the guidelines of the Declaration of Helsinki and approved by the Ethics Committee and Vice-Rectorate for Research and Knowledge Transfer of the University of Alicante (UA-2020-05-12).

Informed Consent Statement: Informed consent was obtained from all subjects involved in the study.

Data Availability Statement: The authors provide a link where the data base supporting the reported results can be found: Flipped Classroom: Active Methodology for Sustainable Learning in Higher Education during Social Distancing Due to COVID-19 (Data Base). Available online: https:/ / docs.google.com/ spreadsheets/d/167mcYs37WQIIUnV4YumXLIW9WS-b4UCbL-EHnCD0ZNA/edit?usp=sharing (accessed on 10 May 2021).

Acknowledgments: The authors extend sincere gratitude to all the university professors who participated in the study and the anonymous referees for the time and effort dedicated to their reviews.

Conflicts of Interest: The authors declare no conflict of interest.

Appendix A

Questionnaire

Flipped Classroom: Active Methodology for Sustainable Learning

in Higher Education during Social Distancing Due to COVID-19

\begin{tabular}{ccc}
\hline & Block 0: Exploratory information & \\
\hline Item & Question & Response \\
\hline 1 & Indicate your sex & Man \\
\cline { 2 - 3 } & & Woman \\
\hline
\end{tabular}




\section{Questionnaire}

Flipped Classroom: Active Methodology for Sustainable Learning in Higher Education during Social Distancing Due to COVID-19

2 Indicate your age

Block 1: Knowledge of Flipped Classroom

3

Do you know the educational methodology called Flipped Classroom?

Yes

No

\section{Block 2: Definition of Flipped Classroom}

Block 3: Implementation of Flipped Classroom before social distancing

\begin{tabular}{c} 
Never \\
\hline Low frequency \\
\hline Medium frequency \\
\hline High frequency \\
\hline Always
\end{tabular}

When implementing Flipped Classroom before social distancing, how often did you use the following teaching resources to promote theoretical learning at home (Videos, audios, texts, etc.) prior to hands-on learning in class?

Never

$5 \quad$ Ad Hoc videos or videos made specifically for your Flipped Classroom sessions.

\begin{tabular}{|c|}
\hline Never \\
\hline Low frequency \\
\hline Medium frequency \\
\hline High frequency \\
\hline Always \\
\hline Never \\
\hline Low frequency \\
\hline Medium frequency \\
\hline High frequency \\
\hline Always \\
\hline Never \\
\hline Low frequency \\
\hline Medium frequency \\
\hline High frequency \\
\hline Always \\
\hline Never \\
\hline Low frequency \\
\hline Medium frequency \\
\hline High frequency \\
\hline Always \\
\hline Never \\
\hline Low frequency \\
\hline Medium frequency \\
\hline High frequency \\
\hline
\end{tabular}




\section{Questionnaire}

Flipped Classroom: Active Methodology for Sustainable Learning in Higher Education during Social Distancing Due to COVID-19

Block 4: Implementation of Flipped Classroom during social distancing

10

11
Do you consider that the current situation, virtual teaching due to social distancing, favours the implementation of educational methodologies such as Flipped?
Never

Low frequency

Medium frequency

High frequency

Always

No. I believe that the current situation does not favour the implementation of educational methodologies such as Flipped Classroom.

Yes. However, I believe that the current situation favours the implementation of other educational methodologies over Flipped Classroom.

Yes. I believe that the current situation favours the implementation of both Flipped Classroom and other educational methodologies.

Yes. I believe that the current situation favours Flipped Classroom implementation over other educational methodologies.

When implementing Flipped Classroom during social distancing, how often do you use the following teaching resources to promote theoretical learning (Videos, audios, texts, etc.) prior to hands-on learning during the virtual class?

12

Ad Hoc videos or videos made specifically for your Flipped Classroom sessions.

No-Ad Hoc videos or videos not prepared specifically for your Flipped

Classroom sessions.

Never

\begin{tabular}{c} 
Never \\
\hline Low frequency \\
\hline Medium frequency \\
\hline High frequency \\
\hline Always \\
\hline Never \\
\hline Low frequency \\
\hline Medium frequency \\
\hline High frequency \\
\hline Always \\
\hline Never \\
\hline Low frequency \\
\hline Medium frequency \\
\hline High frequency \\
\hline Always
\end{tabular}




\section{Questionnaire}

Flipped Classroom: Active Methodology for Sustainable Learning in Higher Education during Social Distancing Due to COVID-19

\begin{tabular}{c} 
Never \\
\hline Low frequency \\
\hline Medium frequency \\
\hline High frequency \\
\hline Always \\
Never \\
\hline Low frequency \\
\hline Medium frequency \\
\hline High frequency \\
\hline Always
\end{tabular}

Do you consider that the current situation, virtual teaching due to social distancing, promotes the development of teaching skills related to educational methodologies such as Flipped Classroom, for example, the Digital Competence?
No. I believe that the current situation does not promote the development of teaching skills related to educational methodologies such as Flipped Classroom.

Yes. However, I believe that the current situation favours the development of teaching skills related to other educational methodologies over Flipped Classroom.

Yes. I believe that the current situation promotes the development of teaching skills for both Flipped Classroom and other educational methodologies

Yes. I consider that the current situation promotes the development of teaching skills related to Flipped Classroom over other educational methodologies.

Block 5: Future considerations

From your professional opinion as professor at the Faculty of Education Sciences of the University of Malaga, do you consider that the current situation, virtual teaching due to social distancing, favouring the implementation of educational methodologies such as Flipped Classroom and developing related teaching skills, could help improve the quality of university education after social distancing?
No. I believe that the situation has not favoured the implementation of educational methodologies such as Flipped Classroom and has not developed related teaching skills; therefore, for these reasons, it will not improve the quality of university education after social distancing.

No. I believe that the current situation has favoured the implementation of educational methodologies such as Flipped Classroom and has developed related teaching skills; however, the quality of university education will not improve for these reasons after social distancing.

Yes. I believe that the current situation has favoured the implementation of educational methodologies such as Flipped Classroom and has developed related teaching skills; therefore, for these reasons, it will improve the quality of university education after social distancing. 


\section{Appendix B}

Table A1. Distribution of the frequency of Flipped Classroom teaching resources before social distancing.

\begin{tabular}{|c|c|c|c|c|c|c|c|c|c|c|}
\hline \multirow{4}{*}{$\begin{array}{c}\text { Flipped Classroom } \\
\text { Teaching Resources } \\
\text { Frequency }\end{array}$} & \multicolumn{10}{|c|}{ Type of Resource } \\
\hline & \multicolumn{4}{|c|}{ Video } & \multicolumn{4}{|c|}{ Slides } & \multirow{2}{*}{\multicolumn{2}{|c|}{ Text }} \\
\hline & \multicolumn{2}{|c|}{ Ad Hoc } & \multicolumn{2}{|c|}{ No Ad Hoc } & \multicolumn{2}{|c|}{ Audio } & \multicolumn{2}{|c|}{ No Audio } & & \\
\hline & $n$ & $\%$ & $n$ & $\%$ & $n$ & $\%$ & $n$ & $\%$ & $n$ & $\%$ \\
\hline Never $^{1}$ & 22 & 48.9 & 10 & 22.2 & 25 & 55.6 & 9 & 20.0 & 5 & 11.1 \\
\hline Low frequency ${ }^{2}$ & 8 & 17.8 & 15 & 33.3 & 5 & 11.1 & 6 & 13.3 & 7 & 15.6 \\
\hline Medium frequency ${ }^{3}$ & 9 & 20.0 & 9 & 20.0 & 8 & 17.8 & 10 & 22.2 & 12 & 26.7 \\
\hline High frequency ${ }^{4}$ & 4 & 8.9 & 9 & 20.0 & 5 & 11.1 & 12 & 26.7 & 13 & 28.9 \\
\hline Always ${ }^{5}$ & 2 & 4.4 & 2 & 4.4 & 2 & 4.4 & 8 & 17.8 & 8 & 17.8 \\
\hline
\end{tabular}

${ }^{1}$ No or almost no sessions; ${ }^{2}$ Less than half of the sessions; ${ }^{3}$ Half of the sessions; ${ }^{4}$ More than half of the sessions; ${ }^{5}$ All or almost all sessions.

Table A2. Distribution of the frequency of Flipped Classroom teaching resources during social distancing.

\begin{tabular}{|c|c|c|c|c|c|c|c|c|c|c|}
\hline \multirow{4}{*}{$\begin{array}{c}\text { Flipped Classroom } \\
\text { Teaching Resources } \\
\text { Frequency }\end{array}$} & \multicolumn{10}{|c|}{ Type of Resource } \\
\hline & \multicolumn{4}{|c|}{ Video } & \multicolumn{4}{|c|}{ Slides } & \multirow{2}{*}{\multicolumn{2}{|c|}{ Text }} \\
\hline & \multicolumn{2}{|c|}{ Ad Hoc } & \multicolumn{2}{|c|}{ No Ad Hoc } & \multicolumn{2}{|c|}{ Audio } & \multicolumn{2}{|c|}{ No Audio } & & \\
\hline & $n$ & $\%$ & $n$ & $\%$ & $n$ & $\%$ & $n$ & $\%$ & $n$ & $\%$ \\
\hline Never $^{1}$ & 19 & 42.2 & 5 & 11.1 & 17 & 37.8 & 10 & 22.2 & 4 & 8.9 \\
\hline Low frequency ${ }^{2}$ & 8 & 17.8 & 12 & 26.7 & 7 & 15.6 & 8 & 17.8 & 7 & 15.6 \\
\hline Medium frequency ${ }^{3}$ & 8 & 17.8 & 13 & 28.9 & 8 & 17.8 & 8 & 17.8 & 11 & 24.4 \\
\hline High frequency 4 & 7 & 15.6 & 10 & 22.2 & 6 & 13.3 & 11 & 24.4 & 16 & 35.6 \\
\hline Always ${ }^{5}$ & 3 & 6.7 & 5 & 11.1 & 7 & 15.6 & 8 & 17.8 & 7 & 15.6 \\
\hline
\end{tabular}

${ }^{1}$ No or almost no sessions; ${ }^{2}$ Less than half of the sessions; ${ }^{3}$ Half of the sessions; ${ }^{4}$ More than half of the sessions; ${ }^{5}$ All or almost all sessions.

Table A3. Difference between the frequency before and during social distancing of Flipped Classroom didactic resources.

\begin{tabular}{|c|c|c|c|c|c|c|c|c|c|c|}
\hline \multirow{4}{*}{$\begin{array}{l}\text { Flipped Classroom } \\
\text { Teaching Resources } \\
\text { Frequency }\end{array}$} & \multicolumn{10}{|c|}{ Type of Resource } \\
\hline & \multicolumn{4}{|c|}{ Video } & \multicolumn{4}{|c|}{ Slides } & \multirow{2}{*}{\multicolumn{2}{|c|}{ Text }} \\
\hline & \multicolumn{2}{|c|}{ Ad Hoc } & \multicolumn{2}{|c|}{ No Ad Hoc } & \multicolumn{2}{|c|}{ Audio } & \multicolumn{2}{|c|}{ No Audio } & & \\
\hline & $n$ & $\%$ & $n$ & $\%$ & $n$ & $\%$ & $n$ & $\%$ & $n$ & $\%$ \\
\hline Never ${ }^{1}$ & -3 & -6.7 & -5 & -11.1 & -8 & -17.8 & 1 & 2.2 & -1 & -2.2 \\
\hline Low frequency ${ }^{2}$ & 0 & 0 & -3 & -6.6 & 2 & 4.5 & 2 & 4.5 & 0 & 0 \\
\hline Medium frequency ${ }^{3}$ & -1 & -2.2 & 4 & 8.9 & 0 & 0 & -2 & 4.4 & -1 & -2.3 \\
\hline High frequency ${ }^{4}$ & 3 & 6.7 & 1 & 2.2 & 1 & 2.2 & -1 & -2.3 & 3 & 6.7 \\
\hline Always 5 & 1 & 2.2 & 3 & 6.7 & 5 & 11.2 & 0 & 0 & -1 & -2.2 \\
\hline
\end{tabular}

${ }^{1}$ No or almost no sessions; ${ }^{2}$ Less than half of the sessions; ${ }^{3}$ Half of the sessions; ${ }^{4}$ More than half of the sessions; ${ }^{5}$ All or almost all sessions.

Table A4. Teaching professionals' personal considerations.

\begin{tabular}{|c|c|c|c|c|}
\hline Item & Question $^{1}$ & Response $^{2}$ & $\mathrm{n}$ & $\%$ \\
\hline \multirow{4}{*}{11} & \multirow{4}{*}{$\begin{array}{l}\text { Educational } \\
\text { methodology }\end{array}$} & $\begin{array}{l}\text { It does not favour the implementation of educational } \\
\text { methodologies such as Flipped Classroom. }\end{array}$ & 3 & 6.7 \\
\hline & & $\begin{array}{l}\text { It does favour the implementation of other educational } \\
\text { methodologies over Flipped Classroom. }\end{array}$ & 3 & 6.7 \\
\hline & & $\begin{array}{l}\text { It does favour the implementation of both Flipped Classroom and } \\
\text { other educational methodologies. }\end{array}$ & 31 & 68.9 \\
\hline & & $\begin{array}{l}\text { It does favour implementation of Flipped Classroom over other } \\
\text { educational methodologies. }\end{array}$ & 8 & 17.8 \\
\hline
\end{tabular}


Table A4. Cont.

\begin{tabular}{|c|c|c|c|c|}
\hline Item & Question $^{1}$ & Response $^{2}$ & $\mathbf{n}$ & $\%$ \\
\hline \multirow{4}{*}{17} & \multirow{4}{*}{ Teaching skills } & $\begin{array}{l}\text { It does not favour the development of teaching skills related to } \\
\text { educational methodologies such as Flipped Classroom. }\end{array}$ & 1 & 2.2 \\
\hline & & $\begin{array}{l}\text { It does promote the development of teaching skills related to other } \\
\text { educational methodologies over Flipped Classroom. }\end{array}$ & 4 & 8.9 \\
\hline & & $\begin{array}{l}\text { It does promote the development of teaching skills for both } \\
\text { Flipped Classroom and other educational methodologies. }\end{array}$ & 30 & 66.7 \\
\hline & & $\begin{array}{l}\text { It does promote the development of teaching skills related to } \\
\text { Flipped Classroom over other educational methodologies. }\end{array}$ & 10 & 22.2 \\
\hline \multirow{3}{*}{18} & \multirow{3}{*}{$\begin{array}{l}\text { Future } \\
\text { considerations }\end{array}$} & $\begin{array}{l}\text { It has not favoured Flipped Classroom and will not improve the } \\
\text { quality of university education. }\end{array}$ & 5 & 11.1 \\
\hline & & $\begin{array}{l}\text { It has favoured Flipped Classroom, but it will not improve the } \\
\text { quality of university education. }\end{array}$ & 13 & 28.9 \\
\hline & & $\begin{array}{l}\text { It has favoured Flipped Classroom and will improve the quality of } \\
\text { university education. }\end{array}$ & 27 & 60 \\
\hline
\end{tabular}

${ }^{1}$ Check the questionnaire (Appendix A) to see the full question. ${ }^{2}$ Check the questionnaire (Appendix A) to see the full response.

\section{References}

1. World Health Organization Disease Outbreak News. Available online: https://www.who.int/csr/don/14-january-2020-novelcoronavirus-thailand-ex-china/en/ (accessed on 15 March 2020).

2. World Health Organization Coronavirus Disease (COVID-2019) Situation Reports. Available online: https://www.who.int/ emergencies/diseases/novel-coronavirus-2019/situation-reports (accessed on 15 March 2020).

3. University of Málaga Información COVID-19 Comunicados Oficiales. Available online: https://www.uma.es/informacioncovid-19/info/123072/comunicados-oficiales / (accessed on 22 March 2020).

4. United Nations Educational, Scientific and Cultural Organization COVID-19 Impact on Education. Available online: https: / / en.unesco.org/covid19/educationresponse (accessed on 15 March 2020).

5. Government of Spain. Real Decreto 463/2020, de 14 de Marzo, por el que se declara el Estado de Alarma para la Gestión de la Situación de Crisis Sanitaria ocasionada por la COVID-19; BOE-A-2020-3692; Agencia Estatal Boletín Oficial del Estado: Madrid, Spain, 2020.

6. Government of Spain Publications Catalog. Available online: https://cpage.mpr.gob.es/catalogo-de-publicaciones/ (accessed on 4 April 2020).

7. Hernández, D.J.; Ortiz, J.J.G.; Abellán, M.T. Metodologías Activas en la Universidad y su relación con los Enfoques de Enseñanza. Profesorado 2020, 24, 76-94. [CrossRef]

8. Klingberg, L. Introducción a la Didáctica General; Pueblo y Educación: Ciudad de la Habana, Cuba, 1978.

9. Gómez, P. Criterios de conceptualización, clasificación, selección y caracterización de los métodos de enseñanza (Revisión). Olimpia 2018, 15, 168-182.

10. Pujol, J.; Fons, J. Los Métodos en la Enseñanza Universitaria; Ediciones Universidad de Navarra: Pamplona, Spain, 1978; ISBN 978-843-130-505-5.

11. García, F.J. Los Modelos Didácticos como Instrumentos de Análisis y de Intervención en la Realidad Educativa. Biblio. 3W 2000. [CrossRef]

12. Homero, G.; Sosa, M.R.; Martínez, F. Modelos Didácticos en la Educación Superior: Una realidad que se puede cambiar. Profesorado 2018, 22, 447-469. [CrossRef]

13. University of Málaga Guía de Docencia Online COVID-19. Available online: https://campusvirtual.uma.es/index.php?option= com_content\&view=article\&id=400\&Itemid=437 (accessed on 22 March 2020).

14. Scriven, M. The Methodology of Evaluation. In Perspectives of Curriculum Evaluation; Tyler, R.W., Gagné, R.M., Scriven, M., Eds.; Rand McNally: Chicago, IL, USA, 1967; pp. 39-83. ISBN 978-052-861-810-9.

15. Castillo, S.; Cabrerizo, J. Evaluación Eeducativa de Aaprendizajes y Competencias; Pearson Educación: Madrid, Spain, 2010; ISBN 978-848-322-667-4.

16. Sánchez, M.; Martínez, A. Evaluación del y para el Aprendizaje: Instrumentos y Estrategias; Imagia Comunicación: Ciudad de México, México, 2020; ISBN 978-607-30-2354-2.

17. Fernández, J. ¿Evaluación? No, gracias, calificación. Cuad. Pedagog. 1996, 243, 92-97.

18. Trigueros, C.; Rivera, E.; De la Torre, E. La Evaluación en el Aula Universitaria: Del Examen Tradicional a la Autoevaluación. Rev. Int. Med. Cienc. Act. Fís. Deporte 2012, 12, 473-491.

19. Pascual, M.P. El Blended Learning reduce el ahorro de la formación on-line pero gana en calidad. Educaweb 2003, $69,34-49$.

20. Bonk, C.J.; Graham, C.R. The Handbook of Blended Learning Environments: Global Perspectives, Local Designs; Jossey-Bass: San Francisco, CA, USA, 2006; ISBN 978-0-787-97758-0.

21. Horn, M.B.; Staker, H. Blended: Using Disruptive Innovation to Improve Schools; Jossey-Bass: San Francisco, CA, USA, 2014; ISBN 978-111-895-515-4. 
22. King, A. From sage on the stage to guide on the side. Coll. Teach. 1993, 41, 30-35. [CrossRef]

23. Bergmann, J.; Sams, A. Dale la Vuelta a tu Clase: Lleva tu Clase a Cada Estudiante, en Cualquier Momento y Cualquier Lugar; SM: Madrid, Spain, 2014; ISBN 978-846-756-118-0.

24. Tourón, J.; Santiago, R. El modelo Flipped Learning y el desarrollo del talento en la escuela. Rev. Educ. 2015, 196-231. [CrossRef]

25. Yang, L. Research on Flipped Classroom Online Teaching under the background of epidemic situation. Int. J. Educ. Econ. Dev. 2020, 3, 44-47.

26. Miller, G.A. The magical number seven, plus or minus two: Some limits on our capacity for processing information. Psychol. Rev. 1956, 63, 81-97. [CrossRef] [PubMed]

27. Sweller, J. Cognitive load during problem solving: Effects on learning. Cogn. Sci. 1988, 12, 257-285. [CrossRef]

28. Mayer, R.E. Multimedia Learning; Cambridge University Press: Cambridge, UK, 2009; ISBN 978-052-173-535-3.

29. Abeysekera, L.; Dawson, P. Motivation and cognitive load in the flipped classroom: Definition, rationale and a call for research. High. Educ. Res. Dev. 2014, 34, 1-14. [CrossRef]

30. Brown, A.F. A Phenomenological Study of Undergraduate Instructors Using the Inverted or Flipped Classroom Model; Pepperdine: University, CA, USA, 2012.

31. Mazur, E. Peer Instruction: A User's Manual Series in Educational Innovation; Prentice Hall: Hoboken, NJ, USA, 1997; ISBN 978-013-565-441-5.

32. Novak, G.N.; Patterson, E.T.; Gavrin, A.; Christian, W. Just-in-Time Teaching: Blending Active Learning and Web Technology; Prentice Hall: Hoboken, NJ, USA, 1999; ISBN 978-013-085-034-8.

33. Fidalgo, Á.; Sein, M.L.; García, F.J. Flipped Classroom, Flip Teaching, Aula Invertida, Aula Inversa. Zenodo 2019. [CrossRef]

34. Fernández, S.E. Flipped Classroom: Aplicación Práctica empleando Lessons en las Prácticas de Laboratorio de una Asignatura de Ingeniería. Ardin 2020, 27-48. [CrossRef]

35. Piaget, J. Psicología de la Inteligencia; Psique: Buenos Aires, Argentina, 1967; ISBN 978-987-629-350-1.

36. Kilpatrick, W.H. The Project Method. Teach. Coll. Rec. 1918, 19, 319-335.

37. Barrows, H.S. Problem-Based Learning in medicine and beyond: A brief overview. New Dir. Teach. Learn. 1996, 3-12. [CrossRef]

38. Swartz, R.J.; Parks, S. Infusing the Teaching of Critical and Creative Thinking into Content Instruction: A Lesson Design Handbook for the Elementary Grades; Critical Thinking Press and Software: Ciudad de México, México, 1994; ISBN 978-089-455-481-0.

39. Vygotsky, L.S. El Desarrollo de los Procesos Psicológicos Superiores; Grijalbo: Barcelona, Spain, 1979; ISBN 978-840-800-694-7.

40. Johnson, D.W.; Johnson, R.T.; Smith, K.A. Cooperative Learning: Increasing College Faculty Instructional Productivity; Jossey-Bass: San Francisco, CA, USA, 1991; ISBN 978-187-838-009-8.

41. Cohen, E.G. Designing Group-Work: Strategies for the Heterogeneous Classroom; Teachers College Press: New York, NY, USA, 1994; ISBN 978-080-775-566-2.

42. Google Trends. Flipped Classroom. Available online: https://trends.google.es / trends / explore?date=all\&q=\%2Fm $\% 2 \mathrm{~F} 0 \mathrm{~h} 68 \mathrm{qds}$ (accessed on 28 April 2021).

43. Garay, L.W.P.; Soto, D.M. From traditional learning to Flipped learning as a continuity of the educational process in the context of COVID-19. Rev. Mendive 2021, 19, 214-226.

44. Lapitan Jr, L.D.; Tiangco, C.E.; Sumalinog, D.A.G.; Sabarillo, N.S.; Diaz, J.M. An effective blended online teaching and learning strategy during the COVID-19 pandemic. Educ. Chem. Eng. 2021, 35, 116-131. [CrossRef]

45. De Pietro, D.M.; Santucci, S.E.; Harrison, N.E.; Kiefer, R.M.; Trerotola, S.O.; Sudheendra, D.; Shamimi-Noori, S. Medical Student Education During the COVID-19 Pandemic: Initial Experiences Implementing a Virtual Interventional Radiology Elective Course. Acad. Radiol. 2021, 28, 128-135. [CrossRef]

46. Janssen, C.H.C. El aula invertida en tiempos del COVID-19. Educ. Quimica 2020, 31, 173-178. [CrossRef]

47. Guraya, S. Combating the COVID-19 outbreak with a technology-driven e-flipped classroom model of educational transformation. J. Taibah Univ. Med. Sci. 2020, 15, 253-254. [CrossRef] [PubMed]

48. Chen, C.H.; Mullen, A.J. COVID-19 Can Catalyze the Modernization of Medical Education. JMIR Med. Educ. 2020, 6, e19725. [CrossRef]

49. Donitsa-Schmidt, S.; Ramot, R. Opportunities and challenges: Teacher education in Israel in the Covid-19 pandemic. J. Educ. Teach. 2020, 46, 586-595. [CrossRef]

50. Torres Martín, C.; Acal, C.; El Honrani, M.; Mingorance Estrada, Á.C. Impact on the Virtual Learning Environment Due to COVID-19. Sustainability 2021, 13, 582. [CrossRef]

51. Latorre-Cosculluela, C.; Suárez, C.; Quiroga, S.; Sobradiel-Sierra, N.; Lozano-Blasco, R.; Rodríguez-Martínez, A. Flipped Classroom model before and during COVID-19: Using technology to develop 21st century skills. Interact. Technol. Smart Educ. 2021. [CrossRef]

52. Sakti, R.H.; Sukardi, S. Empirical Study of Flipped Classroom-Based E-Learning to Face Learning on Covid-19 Pandemic: Empirical Effect. J. Pendidik. Pengajaran 2021, 54. [CrossRef]

53. Marina, H.; Ridlo, S. The Effectiveness of Flipped Classroom to Improve Students' Concept Understanding and Self Efficacy during the Covid-19 Pandemic. Unnes. J. Biol. Educ. 2021, 10, 70-76. [CrossRef]

54. Serrano, J. Aplicación On-line y Tratamiento Informático de Cuestionarios. Rev. Espanola de Pedagog. 2012, 70, 61-75.

55. Chick, R.C.; Clifton, G.T.; Peace, K.M.; Propper, B.W.; Hale, D.F.; Alseidi, A.A.; Vreeland, T.J. Using technology to maintain the education of residents during the COVID-19 pandemic. J. Surg. Educ. 2020, 77, 729-732. [CrossRef] 
56. Iyer, P.ç.; Aziz, K.; Ojcius, D.M. Impact of COVID-19 on dental education in the United States. J. Dent. Educ. 2020, 84, 718-722. [CrossRef]

57. Go, B.; Rajasekaran, K. Effect of COVID-19 in selecting otolaryngology as a specialty. Head Neck 2020, 42, 1409-1410. [CrossRef] [PubMed]

58. Ehrlich, H.; McKenney, M.; Elkbuli, A. We asked the experts: Virtual Learning in Surgical Education during the COVID-19 pandemic. Shaping the future of Surgical Education and Training. World J. Surg. 2020, 44, 2053-2055. [CrossRef]

59. Telles-Langdon, D.M. Transitioning university courses online in response to COVID-19. J. Pract. Teach. Learn. 2020, 14, 108-119. [CrossRef]

60. Alvarez, E.S.; Romero, J.V.; Martín, A.P. Experiencias de Docencia Virtual en Facultades de Medicina Españolas durante la pandemia COVID-19 (II): Farmacología, Inmunología. Edu. Med. 2020, 1, 74-81. [CrossRef]

61. Moszkowicz, D.; Duboc, H.; Dubertret, C.; Roux, D.; Bretagnol, F. Daily medical education for confined students during coronavirus disease 2019 pandemic: A simple videoconference solution. Clin. Anat. 2020, 33, 927-928. [CrossRef] [PubMed]

62. Dedeilia, A.; Sotiropoulos, M.G.; Hanrahan, J.G.; Janga, D.; Dedeilias, P.; Sideris, M. Medical and surgical education challenges and innovations in the COVID-19 era: A systematic review. In Vivo 2020, 34, 1603-1611. [CrossRef]

63. Langford, M.; Damşa, C. Online Teaching in the Time of COVID-19: Academic Teachers' Experience in Norway; Centre for Experiential Legal Learning, University of Oslo: Oslo, Norway, 2020.

64. Karalis, T.; Raikou, N. Teaching at the times of COVID-19: Inferences and Implications for Higher Education Pedagogy. Int. J. Acad. Res. Bus. Soc. Sci. 2020, 10, 479-493. [CrossRef]

65. Mukhtar, K.; Javed, K.; Arooj, M.; Sethi, A. Advantages, Limitations and Recommendations for online learning during COVID-19 pandemic era. Pak. J. Med. Sci. 2020, 36, S27-S31. [CrossRef]

66. Naresh, R. Education after COVID-19 Crisis Based on ICT Tools. Purakala 2020, 31, 464-468.

67. Lin, W.; Chen, Y.; Shi, S.; Liang, J.; Huang, H.; Li, L.; Chen, G. Thoughts on Higher Medical Education under major public health emergencies: Thinking ahead after COVID-19 outbreak. Med. Rxiv. 2020. [CrossRef]

68. Ashokka, B.; Ong, S.Y.; Tay, K.H.; Loh, N.H.W.; Gee, C.F.; Samarasekera, D.D. Coordinated responses of academic medical centres to pandemics: Sustaining medical education during COVID-19. Med. Teach. 2020, 42, 762-771. [CrossRef] [PubMed]

69. Reyna, J. Twelve tips for COVID-19 friendly learning design in medical education. Med. Ed. Publish. 2020, 9. [CrossRef]

70. Huang, R.H.; Liu, D.J.; Guo, J.; Yang, J.F.; Zhao, J.H.; Wei, X.F.; Knyazeva, S.; Li, M.; Zhuang, R.X.; Looi, C.K.; et al. Guidance on Flexible Learning during Campus Closures: Ensuring Course Quality of Higher Education in COVID-19 outbreak; Smart Learning Institute of Beijing Normal University: Beijing, China, 2020.

71. Carreira, S. La Voz de Galicia Experimento de Enseñanza Virtual. Available online: https://www.lavozdegalicia.es/ noticia/galicia/2020/02/18/experimento-flipped-280-millones-estudiantes/00031582041163081507984.htm (accessed on 25 September 2020).

72. Marinoni, G.; Van't Land, H.; Jensen, T. The Impact of COVID-19 on Higher Education around the World; International Association of Universities: Paris, France, 2020.

73. Classroom Window \& Flipped Learning Network. Flipped Classrooms: Improved Test Scores and Teacher Satisfaction. Available online: http:/ / classroomwindow.com (accessed on 28 September 2020). 